\title{
All-laser bladeless cataract surgery, combining femtosecond and nanosecond lasers: a novel surgical technique
}

This article was published in the following Dove Press journal:

Clinical Ophthalmology

12 September 2013

Number of times this article has been viewed

\section{Anastasios John \\ Kanellopoulos}

LaserVision gr Institute, Athens, Greece; New York University Medical School, New York, NY, USA

\section{Video abstract}

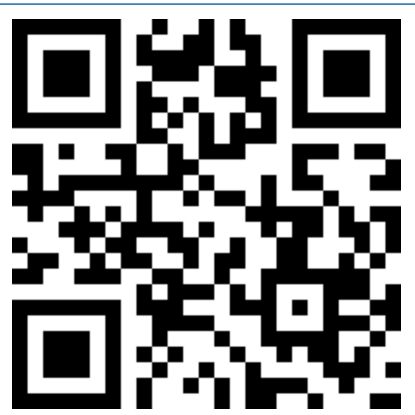

Point your SmartPhone at the code above. If you have a QR code reader the video abstract will appear. Or use: http://dvpr.es//7DGnEH

Correspondence: Anastasios John Kanellopoulos

New York University Medical School,

New York, NY, USA

Tel +302107472777

Fax +302107472789

Email ajk@brilliantvision.com
Purpose: To report the safety and efficacy of a novel surgical technique using two lasers in cataract surgery.

Methods: In this contralateral eye report, a 57-year-old female underwent cataract extraction. Two laser devices and a standard phacoemulsification, platform were used to conduct the procedures. First, a femtosecond laser was used to perform the corneal incision, capsulorhexis, and initial lens fragmentation in each eye. Following this, a nanosecond laser was used to enter the $2.8 \mathrm{~mm}$ incision, uni-axially, and complete the viscoelastic-divided nucleus fragment emulsification and removal in one eye. Standard phacoemulsification was used in the completion of the other eye. Posterior chamber foldable acrylic intraocular lenses were implanted in both cases. We evaluated perioperative acuity, refraction, keratometry, Scheimpflug tomography, intraocular pressure, endothelial cell counts, and total energy used with each laser in each case.

Results: Corrected distance visual acuity improved from preoperative 20/60 and 20/70 to postoperative 20/20 in both eyes, with 6-month follow-up. In the right eye, the total intraocular energy used was $2 \mathrm{~J}$ by the femtosecond laser and $6 \mathrm{~J}$ by the phacoemulsification device. In the left eye, the nanosecond laser utilized the same energy of $2 \mathrm{~J}$ and the nanosecond laser $2.4 \mathrm{~J}$ (80 pulses of $30 \mathrm{~mJ}$ each). There were no other differences noted in intraocular pressure or endothelial cell counts.

Conclusion: In this report, we introduce a bladeless all-laser cataract surgery extraction alternative technique, with several potential novel advantages: enhanced incision and capsulorhexis reproducibility, reduction in intraocular energy used, and elimination of the potential of thermal corneal injury.

Keywords: LenSx ${ }^{\circledR}$ femtosecond laser, Cetus nanosecond laser, energy consumed, smallincision cataract surgery

\section{Introduction}

Colleagues and I have previously reported ${ }^{1,2}$ the use of laser technology to fragment and emulsify the nucleus in cataracts instead of phacoemulsification, with relative success. When introduced in the 1990s, the advantages of this technique were the ability to eliminate corneal thermal damage related to phacoemulsification use and reduce potential corneal endothelial loss induced by phacoemulsification intraocular energy release. The separation of the laser cataract-emulsifying probe from the irrigation source and an advanced intraocular lens pre-folding technique enabled - globally for the first time - the reduction of the main corneal incision to under $2 \mathrm{~mm}^{2}$. Smallincision clear cornea cataract surgery has evolved enormously since then, with the introduction of non-continuous output and torsional phacoemulsification devices 
that utilize a fraction of the energy used in the past. ${ }^{3-6}$ Further, recent advances in femtosecond lasers applied in cataract surgery ${ }^{7,8}$ have provided the ability to complete the procedure without the use of incisional instruments such as blades for the cornea incisions, sutures, sharp cystotomes, and/or sharp capsulorhexis forceps.

Herein, a novel technique is described that combines use of the femtosecond laser (LenSx ${ }^{\circledR}$ Laser, Alcon, Fort Worth, TX, USA) - to create the cornea incisions, effective capsulorhexis, and lens pre-fragmentation - with use of an updated version of a nanosecond laser device, formerly known as the "Photolysis" device and now as the "Cetus" device (A.R.C. Laser, Erlangen, Germany).

\section{Methods}

The Cetus nanosecond laser utilizes fiber optic laser energy transfer from a module stationed beside the operating bed, within the probe, that then internally emits laser energy to the probe edge. The energy produced is used to emulsify and absorb cataract fragments (Figure 1). Both these platforms had already received the $\mathrm{CE}$ (Conformité Européenne) mark for clinical use within the European Union at the time of writing. The novelty of the technique described herein is a change to the sequence of the traditional steps in clear cornea cataract surgery (cornea incision, viscoelastic introduction, capsulorhexis, hydrodissection, hydrodelineation, and then lens fragmentation with a phacoemulsification device).

Two cases of cataract surgery are reported here, which were contralateral eyes of the same patient. The patient was

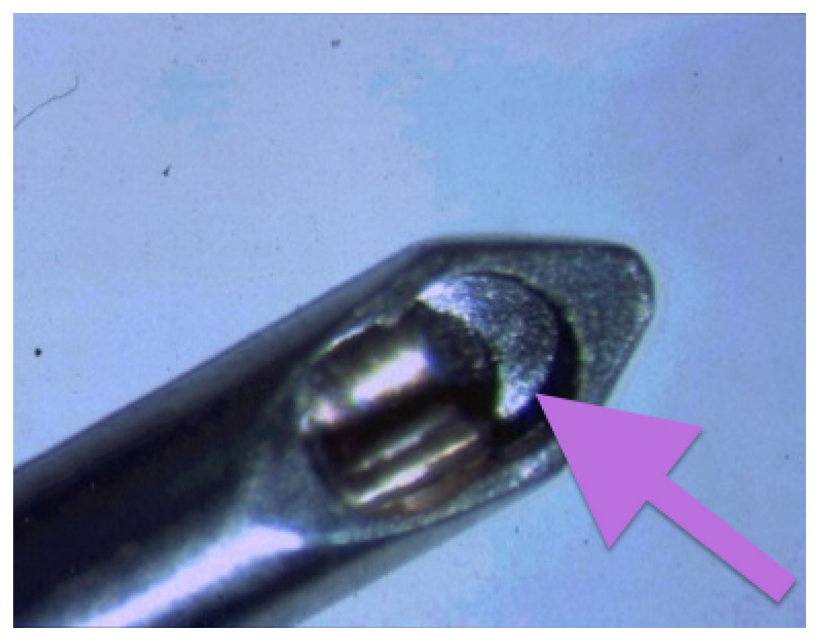

Figure I The inner bore of the Cetus probe (A.R.C. Laser, Erlagen, Germany). The titanium inside edge of the probe is the targeting spot for this nanosecond laser. Pulsing the laser emits a plasma formation, and a focused abrupt ultrasound surge is emitted from this point that extends outwards. The probe serves as the aspiration port as well, thus engaging the cataract fragments. The outer silicone sleeve in the coaxial version of the probe used provides the irrigation. a 57-year-old female who had developed cataracts in both eyes, which caused a reduction in corrected distance visual acuity to $20 / 60$ (refraction $-2.50,-1.00$ at $160^{\circ}$ ) in the right eye and $20 / 70$ (refraction $-3.25,-1.25$ at $10^{\circ}$ ) in the left. Preoperative keratometry values, as measured with the Pentacam (Oculus, Wetzlar, Germany), were 45 and 43 at $165^{\circ}$, and 44.75 and 42.75 at $8^{\circ}$ for the right and left eye, respectively. An AcrySof ${ }^{\circledR}$ Toric (Alcon) intraocular lens was calculated for use in both cases, due to the high keratometric astigmatism assessment preoperatively.

\section{Surgical technique}

With the current femtosecond laser cataract surgery protocol using the LenSx ${ }^{\circledR}$, capsulorhexis is performed first, lens fragmentation second, and cornea incision(s) last. In the novel technique introduced here, the femtosecond laser step is continued beyond, with viscoelastic-assisted separation of the lens fragments; Viscoat ${ }^{\circledR}$ (Alcon) was used to physically separate the four cataract segments that had been predissected but not separated with the femtosecond laser. The free-floating capsulorhexis, achieved in both cases with the LenSx ${ }^{\circledR}$, was removed through the main incision $(2.8 \mathrm{~mm})$ prior to this. Instead of the traditional step of hydrodissection and/or hydrodelineation following the removal of the femtosecond laser-dissected capsulorhexis, additional viscoelastic is administered to bluntly visco-dissect the lens fragments defined by the femtosecond laser.

To facilitate this process, and during the femtosecond laser fragmentation stage, the lens fragmentation is set to be more superior/anterior than the manufacturer's current recommendations, just $50 \mu \mathrm{m}$ under the anterior capsule. Only four crossed radial incisions are programmed in for the femto-lens fragmentation. The posterior border of the lens fragmentation is at least $500 \mu \mathrm{m}$ away from the posterior capsule, in accordance with the manufacturer's suggestion. To avoid potential radial tears to the anterior capsular border due to this setting, the capsulorhexis is set to be wider $(5 \mathrm{~mm})$ than the actual lens fragmentation design (4.8 mm; Figure 2). Therefore, the lens femto-fragmentation may be planned to reach a more superficial level, without fear of incising outside the diameter of the capsulorhexis. This anteriorly planned lens fragmentation allows direct installation of viscoelastic into the femto-incision cataract "lines" and physical "split" of the cataract quadrants without any other instrumentation aid (Figure 3). It is theorized that this may not be a contraindication because the lens fragmentation plan is much more narrow in diameter than the actual capsulorhexis, reducing the potential danger of 


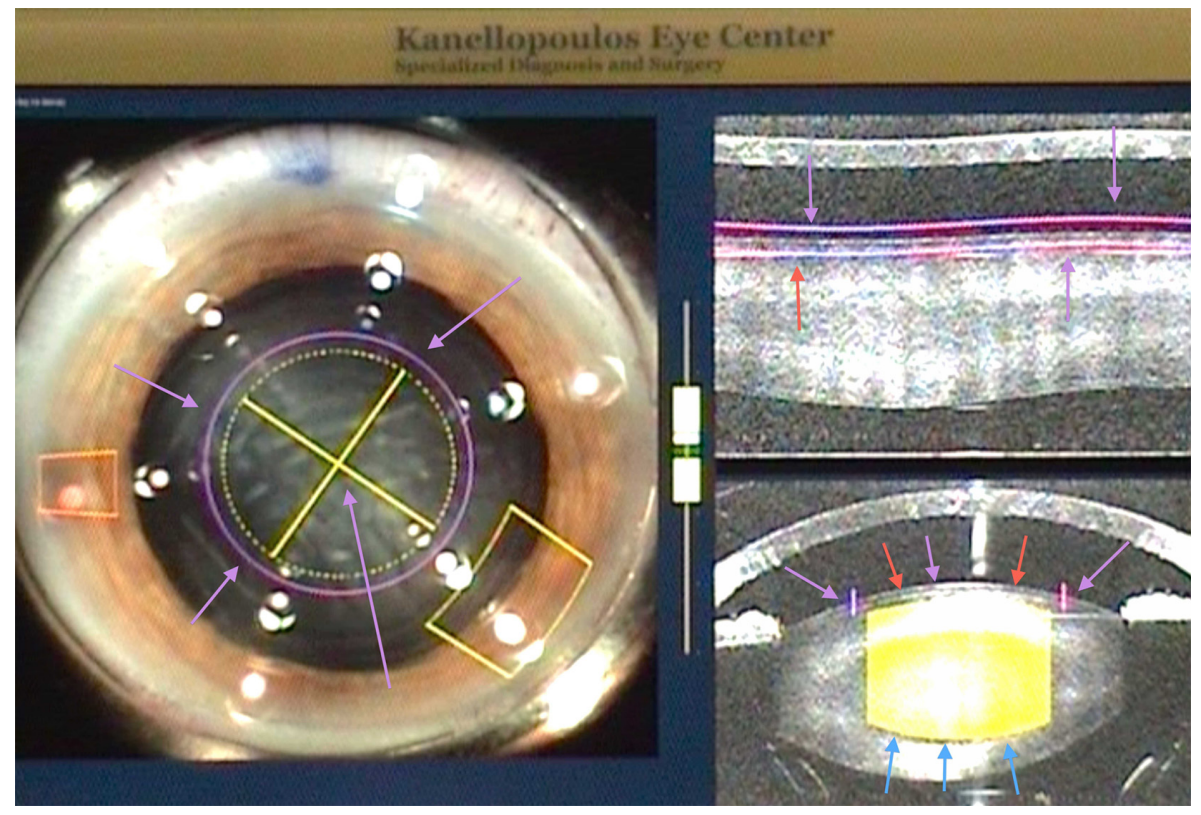

Figure 2 The LenSx ${ }^{\circledR}$ (Alcon, Fort Worth, TX, USA) femtosecond laser capsulorhexis, lens fragmentation, and cornea incision final plan. The capsulorhexis planned is shown by the purple arrows both on the left (coronal) and right (cross-sectional) images of this intraoperative optical coherence tomography planning tool. The lens fragmentation plan is shown by the yellow crosshairs and arrows in the left coronal view. Of note is that the planned lens fragmentation diameter is narrower than the capsulorhexis diameter. On the right view, the lens fragmentation is shown in cross section. Its anterior extent, just under the anterior capsule, is shown by red and magenta arrows. The posterior extent is shown by the blue arrows and is 500 microns short of the posterior capsule.

creating tears in the circular femto-assisted capsulorhexis, as noted.

When standard lens fragmentation settings are used, it is difficult to visco-separate the lens fragments, so intraocular pre-chopping and/or phacoemulsification is needed to achieve this. Following the visco-separation step, some of the viscoelastic is removed through the interior chamber and then

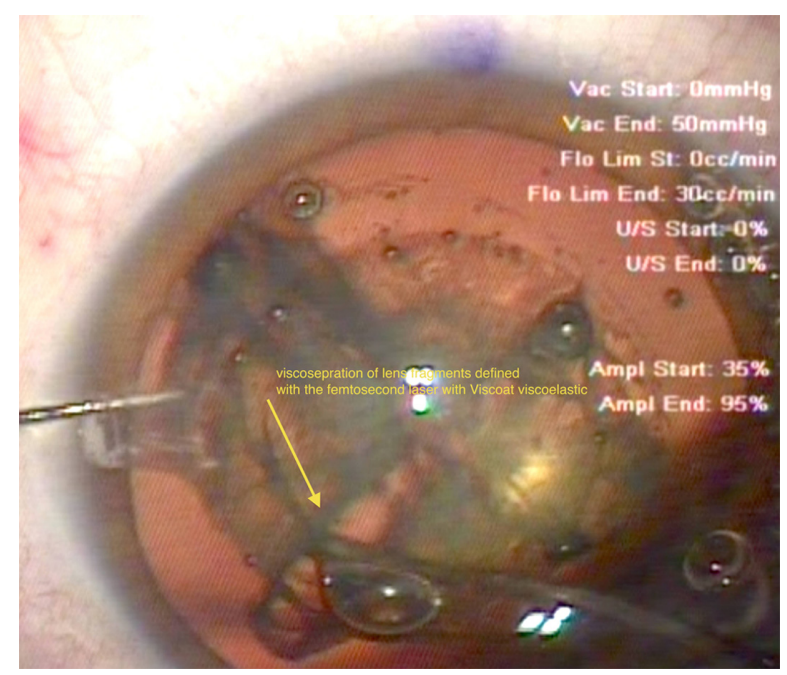

Figure 3 Visco-separation (yellow arrow) of the femto-dissected cataract quadrants. The end of the Viscoat ${ }^{\circledR}$ (Alcon, Fort Worth, TX, USA) irrigation cannula has been inserted in these two cataract quadrants, completing their physical separation. Note the retro-cataract air bubble, which can be seen escaping anteriorly, facilitated by the space created between the visco-separated cataract fragments. a very careful hydrodissection is performed. This invariably "burps" a quarter segment of the separated cataract quadrants within the anterior chamber, thus decompressing the capsular bag and greatly facilitating fragment removal (Figure 4).

Following this, either the Cetus nanosecond laser or the Constellation ${ }^{\circledR}$ phaco coaxial sleeved probe (Alcon) is introduced into the interior chamber and a Sinskey hook inserted through the paracentesis for the manipulation of the further emulsified cataract segments. When the laser device is used, irrigation/aspiration of the mobilized cataract quadrant segment is first performed, bringing it to the pupillary level. Then, during the pulsing of the laser, a short and brisk ultrasound shockwave is generated due to plasma formation from the laser on the titanium tip of the probe, thus emulsifying and absorbing a chunk of the cataract segment, which then further propagates into the probe via the continuous irrigation/aspiration that takes place at the same time (Figure 5).

Engagement of the lens fragments at this stage is simple and brisk due to the large aspiration opening $(0.9 \mathrm{~mm})$ of the Cetus laser probe. The larger aspiration bore created allows it to powerfully "grab" onto the lens fragment and then safely emulsify that fragment before absorbing it through aspiration.

The removal of the subsequent three quadrants of the pre-dissected cataract follows, as there is more room within the capsular bag, and this is completed without any further challenge. After this, the probe is removed from the anterior 


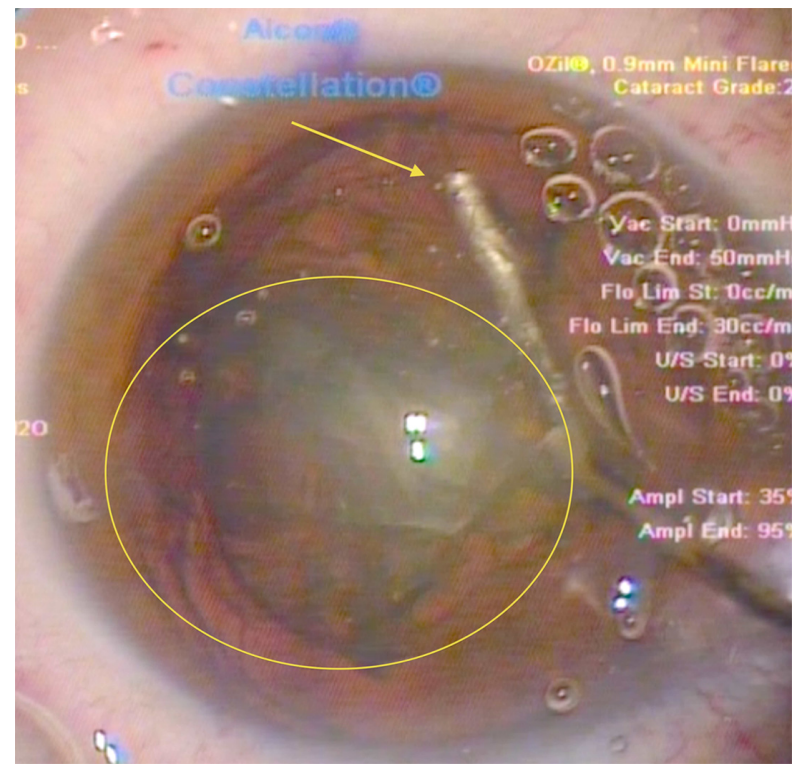

Figure 4 Insertion of the irrigation cannula just under the capsulorhexis at the 6 o'clock position (12 o'clock in this surgeon's view) - another novel step in the procedure. The surge of the hydrodissection at this point has "pushed" the separated cataract quadrant (yellow oval) into the pupillary plane. Note again, at this stage of the procedure, the multiple bubbles relocating anteriorly, just under the cornea. These bubbles represent gas produced by the lens fragmentation stage of the femtosecond procedure and have been trapped within the posterior part of the cataract until this stage.

chamber and replaced with a standard irrigation/aspiration probe to remove the residual cortex and polish the underside of the anterior capsule peripheral to the capsulorhexis. This polishing reduces the number of lens epithelial cells present there and the possibility of posterior capsule opacification.

In this particular case, in both eyes, the AcrySof IQ Toric IOL SNAT4 (Alcon) foldable intraocular lens was used following previous marking (executed on a slit lamp with a blue marker) of the steep astigmatic axis. The lens was placed within the capsular bag using a Monarch ${ }^{\circledR}$ D Cartridge Injector (Alcon) and then irrigation/aspiration was performed to remove the residual viscoelastic.

The wounds were closed in both eyes without irrigation or hydration of the corneal stroma, but with placement of a small amount of ReSure Adherent Ocular Bandage (Ocular Therapeutix, Bedford, MA, USA) glue and the anterior chamber filled with BSS (balanced salt solution). Following this, acetylcholine was given, to attain miosis, and topical antibiotics in both eyes (Vigamox [Alcon] and Dispersadron C [Laboratoires Théa, Clermont-Ferrand, France]).

\section{Results}

Corrected distance visual acuity improved from 20/60 in the right eye and $20 / 70$ in the left, preoperatively, to $20 / 20$ in

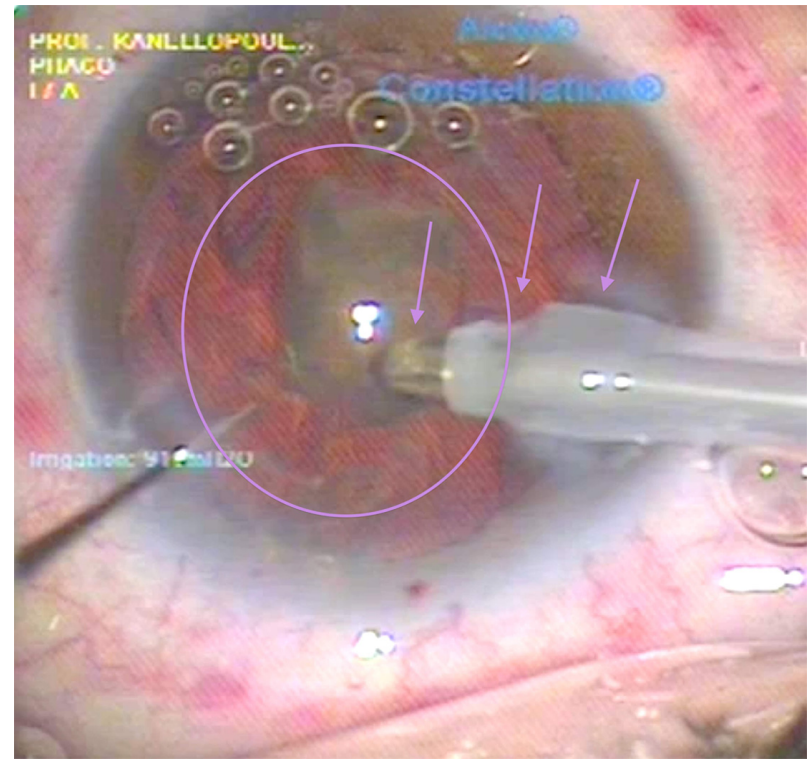

Figure 5 Last step of the nanosecond laser cataract quadrant removal. The last cataract quadrant left within the eye is seen here (purple oval) engaged by the aspiration of the probe (left purple arrow). The middle purple arrow points to one of the two silicone probe sleeve openings providing the coaxial irrigation. Finally, the rightmost purple arrow points to the hydration of the femto-created cornea incision, seen as clouding. This clouding of the incision margins is purely hydration, because this nanosecond laser probe does not emit any heat, as the laser energy is transmitted through fiber optics within the probe and released just at the edge of the probe onto the titanium target within the probe shown in Figure I.

both eyes postoperatively. The 6-month postoperative refraction was $+0.50,-0.75$ at 90 degrees and $+0.25,-0.50$ at 95 degrees in the right and left eye, respectively. The right eye, completed with the phaco, was estimated to have used total phaco energy of $6 \mathrm{~J}$. The left eye was completed with the Cetus device, which utilized 80 pulses of $30 \mathrm{~mJ}$ each (total $2.4 \mathrm{~J}$ ) - significantly less energy than the phaco. Both procedures were completed without incident. Intraocular pressures ranged from 15 to $17 \mathrm{mmHg}$ in both eyes perioperatively and no significant findings in this respect were noted. Endothelial cell counts remained stable - from 1850 and 1800 , to 1750 and 1800 in the right and left eye, respectively. A similar endothelial cell count profile change was observed in the first 6 months following the operation.

\section{Discussion}

Herein, a novel surgical technique for cataract surgery is introduced that reorders the original traditional steps of incision, capsulorhexis, lens fragmentation, and hydrodissection; lens emulsification and removal of the cortex; and intraocular lens implantation. The new procedure begins with capsulorhexis, which is followed by lens visco-separation and hydrodissection. In the second eye, an alternative to phacoemulsification lens removal was utilized. This therefore maximizes the potential 
facility that a femtosecond laser lens fragmentation currently offers in dissecting a cataract by using four segments and physically separating them intraocularly with viscoelastic prior to applying hydrodissection and/ or hydrodelineation.

This new procedure may be safer than manual procedures performed within the capsular bag, even when these are undertaken by experienced surgeons. It appears able to decrease potential superfluous pressure within the capsular bag cased by entrapped gas created during the femtodissection and the rush of fluid needed to accomplish hydrodissection, and also has the potential to reduce tears and rents of the capsular bag. With inadvertent separated cataract fragment expulsion outside the capsular bag, most of the fragment emulsifying procedure is performed at the pupillary aperture. No significant difference was noted in early postoperative healing in lieu of cornea clarity and endothelial cell count change, as already noted. The potential disadvantage of emulsifying the cataract fragments with the Cetus device more anteriorly does not seem to affect the cornea. This is perhaps due to the forward-only energy pulse that this laser creates. This is in contrast to the ultrasound energy area, which almost resembles a sphere, that is emitted from the phacoemulsification probe tip.

\section{Conclusion}

While a potential disadvantage of this technique may be that copious viscoelastic material is required, it is theorized that the technique has several potential significant advantages, including incisional accuracy, both for cornea incisions and capsulorhexis, as well as significantly reduced energy consumption in comparison to phacoemulsification using a nanosecond laser device.
The novel procedure described here may be termed an "all-laser" procedure, as no technology besides lasers is used to perform all stages of the cataract surgery. Further studies and more data are needed to validate these initial feasibility findings.

\section{Disclosure}

The author declares no conflicts of interest in this work.

\section{References}

1. Kanellopoulos AJ, Dodick J, Froman, Brauweiler, Alzner E. Dodick photolysis for cataract surgery: early experience with the Q-switched neodynium: YAG Laser in 100 consecutive patients. Ophthalmology. Nov 1999;106(11):2197-2202.

2. Kanellopoulos AJ. Photolysis Investigative Group. Laser cataract surgery: A prospective evaluation of 1000 consecutive laser cataract procedures using the Dodick photolysis Nd:YAG system. Ophthalmology. Apr 2001;108(4): 649-654; discussion 654-655.

3. Nishi Y, Engler C, Na DR, et al. Evaluation of phacoemulsificationinduced oxidative stress and damage of cultured human corneal endothelial cells in different solutions using redox fluorometry microscopy. Acta Ophthalmol. 2010;88(8):e323-e327.

4. Reuschel A, Bogatsch H, Barth T, Wiedemann R. Comparison of endothelial changes and power settings between torsional and longitudinal phacoemulsification. J Cataract Refract Surg. 2010;36(11):1855-1861.

5. Liu Y, Zeng M, Liu X, et al. Torsional mode versus conventional ultrasound mode phacoemulsification: randomized comparative clinical study. J Cataract Refract Surg. 2007;33(2):287-292.

6. Fishkind W, Bakewell B, Donnenfeld ED, Rose AD, Watkins LA, Olson RJ. Comparative clinical trial of ultrasound phacoemulsification with and without the WhiteStar system. J Cataract Refract Surg. 2006;32(1):45-49.

7. Conrad-Hengerer I, Hengerer FH, Schultz T, Dick HB. Effect of femtosecond laser fragmentation on effective phacoemulsification time in cataract surgery. J Refract Surg. 2012;28(12):879-883.

8. Conrad-Hengerer I, Hengerer FH, Schultz T, Dick HB. Effect of femtosecond laser fragmentation of the nucleus with different softening grid sizes on effective phaco time in cataract surgery. J Cataract Refract Surg. 2012;38(11):1888-1894.
Clinical Ophthalmology

\section{Publish your work in this journal}

Clinical Ophthalmology is an international, peer-reviewed journal covering all subspecialties within ophthalmology. Key topics include: Optometry; Visual science; Pharmacology and drug therapy in eye diseases; Basic Sciences; Primary and Secondary eye care; Patient Safety and Quality of Care Improvements. This journal is indexed on

\section{Dovepress}

PubMed Central and CAS, and is the official journal of The Society of Clinical Ophthalmology (SCO). The manuscript management system is completely online and includes a very quick and fair peer-review system, which is all easy to use. Visit http://www.dovepress.com/ testimonials.php to read real quotes from published authors. 